\title{
Urological abnormalities in young women with severe constipation
}

\author{
J J BANNISTER, W T LAWRENCE, A SMITH, D G THOMAS, \\ AND N W READ
}

From the Department of Surgery and Sub-Dept of Human Gastrointestinal Physiology and Nutrition, Royal Hallamshire Hospital, Sheffield, Department of Urology, Lodge Moor Hospital, Sheffield, and Department of Obstetrics \& Gynaecology, Jessop's Hospital for Women, Sheffield

SUMmaRY Anorectal and urodynamic studies were carried out in 10 young women with severe constipation and the results compared with those obtained in controls. The lowest volumes that provoked a desire to defecate (constipated $200 \pm 50 v$ controls $110 \pm 10$ [mean $\pm \mathrm{SEM}$ ] $\mathrm{ml}: \mathrm{p}<0 \cdot 05$ ), and a desire to micturate (constipated 560 $\pm 40 v$ controls $295 \pm 15$ [mean \pm SEM] ml: $\mathrm{p}<0 \cdot 001$ ), were significantly greater in constipated patients compared with controls. The maximum tolerable rectal volume $(380 \pm 30 v 290 \pm 20$ [mean \pm SEM] ml: $\mathrm{p}<0.05)$ and the bladder capacity $(720 \pm 50 v$ $540 \pm 10$ [mean \pm SEM] $\mathrm{ml}: \mathrm{p}<0 \cdot 001)$ were also increased in the constipated subjects compared with controls. Electromyographic studies show failure of relaxation of the external anal sphincter (EAS) on attempted defecation in all 10 patients; and eight of these patients actually contracted their EAS when they strained to defecate, causing a functional outlet obstruction. Urodynamic studies showed normal urinary flow rates, normal detrusor pressures and normal radiology during voiding. Thus, these studies suggest that constipated patients have an increase in capacity and a reduction in sensitivity in the urinary bladder as well as in the rectum, but showed no evidence of obstruction to urine flow.

In a recent study of 34 young women with severe diet resistant constipation it was noted that a high proportion gave a history of urinary dysfunction. ${ }^{1}$ These symptoms included decreased $(20 \%)$ or increased $(35 \%)$ frequency of micturition, urgency $(29 \%)$, hesitancy $(23 \%)$ and stress incontinence $(26 \%)$. In another study, nocturia and difficulty in initiation of micturition have been reported as common in young women with severe chronic constipation. ${ }^{2}$ Because the innervation and function of the urinary bladder is similar to that of the rectum, it seemed possible that patients with severe constipation, who had well documented abnormalities in anorectal function, would also have analogous findings in bladder function. Few studies have investigated bladder function in constipated patients, although abnormal

Address for correspondence: Mr J J Bannister, Department of Surgery, Royal Hallamshire Hospital, Sheffield S10 2JF.

Received for publication 10 June 1987. bladder responses to bethanechol have been shown in patients, predominantly young women, with 'colonic inertia' ${ }^{3+}$ The aim of these studies was to compare the results of urodynamic and anorectal tests in 10 consecutive patients referred with constipation refractory to conventional measures and in appropriate groups of controls.

\section{Methods}

\section{SUBJECTS}

Ten women (age 33 \pm 3 years [mean \pm SEM] had severe constipation, which was unresponsive to increased supplementation with $30 \mathrm{~g}$ coarse bran per day, and had been present at least one year (range 130 years; median 10 years). Their stool frequency ranged from nil to eight times per month (median four times per month) and during measurement of whole gut transit times, none of them passed any ingested markers in their stools within three days. 
None of the subjects were found to have faecal impaction and barium enemas revealed no obvious pathological features.

The controls for the anorectal studies consisted of 27 asymptomatic female volunteers (age $34 \pm 3$ years, $[$ mean \pm SEM]) selected from members of staff, students, and patients who had been admitted for minor surgery not involving the gastrointestinal system.

Two control groups were used for the urological study, the first consisted of 18 women (age $38 \pm 6$ years [mean $\pm S E M]$ ) undergoing full urological assessment for symptoms of stress incontinence or urgency. These subjects, therefore, had similar symptoms to the constipated patients, but none gave a history of gastrointestinal disturbances or difficulty in defecation. None of these subjects showed any evidence of detrusor instability. The second control group consisted of 58 women (age $37 \pm 1$ year [mean \pm SEM]) with no history of urinary or gastrointestinal disturbances, nor difficulty in defecation. These subjects were part of a study of non-malignant gynaecological disease and all had benign gynaecological conditions not involving the urinary tract or causing any urinary symptoms.

\section{ANORECTAL TESTS}

\section{Response to rectal distension}

A rectal balloon was constructed by tying $10 \mathrm{~cm}$ of unstretched condom (LRC, London) around a semirigid manometric catheter of external diameter 3 $\mathrm{mm} .{ }^{5}$ The tube was inserted so that the caudad pole of the balloon was $6 \mathrm{~cm}$ from the anal margin. The balloon was inflated in $50 \mathrm{ml}$ increments, allowing at least one minute to elapse before introducing a higher volume. At each new volume the sensations experienced by the patients were noted, and the rectal volume that yielded the first desire to defecate and the maximum volume that could be tolerated were recorded. The pressure within the balloon was continuously monitored by means of an air filled transducer connected through a side arm to the rectal catheter. The output of the transducer was amplified and displayed on a chart recorder. The trace was allowed to stabilise for one minute after each new volume was introduced, and rectal pressure for each distending volume was calculated by subtracting the pressure measured during inflation of the balloon outside the patient from the steady state pressure recorded with the balloon in the rectum.

\section{Simulated defecation}

A balloon was constructed from $10 \mathrm{~cm}$ of unstretched condom tied around a semirigid manometric catheter of external diameter $3 \mathrm{~mm}$. This was placed in the rectum and $50 \mathrm{ml}$ warm $\left(37^{\circ} \mathrm{C}\right)$ water infused to fill the balloon.

A bipolar electrode ${ }^{6}$ consisting of two fine trimel coated wires (diameter $0.025 \mathrm{~mm}$ ) with the ends bared and bent over was inserted by means of 21 gauge hypodermic needle into the most superficial part of the external anal sphincter.' Once in place, the needle was withdrawn leaving the wires in place. The wires, which could not be felt by any of the subjects, were connected via an amplifier (DISA Type 14A 11 Electromyograph), and integrator to the chart recorder.

The subject then sat on a commode and was left alone, although the technician was within hailing distance behind a screen. When the subject felt relaxed she attempted to pass the simulated stool, pressing a button, which produced a mark on the trace as she did so. The subject was allowed a maximum of five minutes to attempt to pass the simulated stool. If she was unable to do so within that time, the simulated stool was deflated and withdrawn through the anus.

\section{UROLOGICAL INVESTIGATIONS}

Urological investigation in the constipated patients and symptomatic controls was carried out by means of standard filling and voiding cystometry with radiological screening. ' The bladder was catheterised with two small (OD $2 \mathrm{~mm}$ ) Vigon tubes introduced on a $14 \mathrm{~F}$ Nelaton catheter which was then removed. One of these tubes was used for filling the bladder at 50 $\mathrm{ml} / \mathrm{min}$ with $37^{\circ} \mathrm{C}$ Urografin by a Disa pump. The second was used for measuring the total bladder pressure. A rectal tube was also inserted with a balloon to record rectal pressure. Both the pressure recording tubes were fluid filled and connected through transducers to a Disa multi channel chart recorder. Bladder filling was started with the subject

Table 1 Rectal sensation and simulated defecation

\begin{tabular}{lccc}
\hline & Patients & Controls & \\
\hline $\begin{array}{l}\text { Volume to cause first } \\
\text { desire to defecate }(\mathrm{ml})\end{array}$ & $200 \pm 50$ & $110 \pm 10$ & $\mathrm{p}<0 \cdot 05$ \\
$\begin{array}{c}\text { Maximum tolerable } \\
\text { volume (ml) }\end{array}$ & $380 \pm 30$ & $290 \pm 20$ & $\mathrm{p}<0 \cdot 05$ \\
$\begin{array}{c}\text { Percentage of subjects that } \\
\text { could pass simulated stool }\end{array}$ & $0 \%$ & $100 \%$ & $\mathrm{p}<0 \cdot 01$ \\
$\begin{array}{c}\text { Percentage of subjects that } \\
\text { reduced EAS-EMG activity } \\
\text { on straining }\end{array}$ & $0 \%$ & $62 \%$ & $\mathrm{p}<0 \cdot 05$ \\
$\begin{array}{c}\text { Percentage of subjects that } \\
\text { increased EAS-EMG activity }\end{array}$ & $80 \%$ & $15 \%$ & $\mathrm{p}<0 \cdot 02$ \\
on straining & & & \\
\hline
\end{tabular}

Results expressed as mean $\pm \mathrm{SEM}$; statistical analysis by Student's $t$ test or $\chi^{2}$ test with Yates correction for small numbers. 
Table 2 Rectal pressure during rectal distension

\begin{tabular}{lccc}
\hline & \multicolumn{2}{c}{$\begin{array}{c}\text { Rectal pressures } \\
\mathrm{cm} \mathrm{H}_{2} \mathrm{O} \text { (mean } \pm \text { SEM) }\end{array}$} & \\
\cline { 2 - 3 } Rectal volume & Constipated & Controls & \\
\hline $50 \mathrm{ml}$ & $13 \pm 1$ & $12 \pm 1$ & $\mathrm{NS}$ \\
$100 \mathrm{ml}$ & $15 \pm 1$ & $15 \pm 1$ & NS \\
$150 \mathrm{ml}$ & $19 \pm 1$ & $17 \pm 2$ & NS \\
\hline
\end{tabular}

Statistical analysis by Student's $t$ test NS $=$ not significant $(p>0 \cdot 05)$.

in the supine position. As soon as any bladder fullness was perceived, filling was continued with the subject erect by tilting the $x$-ray table vertically. The volume at first desire to void, and the maximum tolerable volume were noted in each subject. Intravesical and intrarectal pressures were monitored during bladder filling and the pressures were noted when $100,200,300,400$, and $500 \mathrm{ml}$ had been introduced.

When the subject reached their maximum capacity, the subject was allowed to sit on a commode and void their urine. The bed pan was continuously weighed and the total bladder pressure, intrarectal pressure and the change in the weight of the bed pan - that is, flow rate, were continuously measured until all the bladder contents had been voided.

The true vesical pressure was measured during filling and voiding by subtraction of the abdominal pressure, measured by the intrarectal balloon, from the total bladder pressure. Radiological screening was carried out at maximum bladder capacity and during voiding to detect any abnormality of the bladder neck and urethra.

Filling cystometry was done in the asymptomatic control group with the patients in the supine position. Sterile water at body temperature was infused through an 11 French Gaeltec catheter by means of a peristaltic pump. The volume that had been infused when subjects first experienced a desire to micturate and the maximum tolerable bladder capacity were noted. The subjects were then allowed to void normally.

\section{Results}

ANORECTAL STUDIES

\section{Rectal distension}

The lowest volumes required to cause a desire to defecate were higher in the constipated subjects than in the controls $(\mathrm{p}<0.05)$ (Table 1$)$. The maximum tolerable volumes were higher in the constipated subjects than in the controls $(p<0.05)($ Table 1$)$. Rectal pressures during rectal distension were similar for the controls and constipated subjects (Table 2).

\section{Simulated defecation}

All of the control subjects were able to pass the simulated stool and $62 \%$ of them relaxed their EAS during straining. Only $15 \%$ contracted their sphincter as they attempted to pass the balloon. In contrast, none of the constipated subjects were able to expel the simulated stool and none showed a decrease in the electrical activity of the EAS during attempted defecation. Instead, eight of 10 of the constipated subjects increased their EAS electrical activity during straining.

\section{UROLOGICAL STUDIES}

\section{Filling}

The volume that caused the first desire to void was significantly higher in the constipated subjects than in both groups of controls $(p<0.001)$ (Table 3$)$.

The maximum tolerable bladder volume was also significantly higher in the constipated subjects than in both groups of controls $(p<0.001)$ (Table 3$)$.

At capacity, five constipated subjects showed beaking (partial opening) of the bladder neck and of these (three) showed genuine stress incontinence. The bladder pressures during filling were normal with no detrusor instability (Table 4).

Table 3 Bladder sensation and micturition

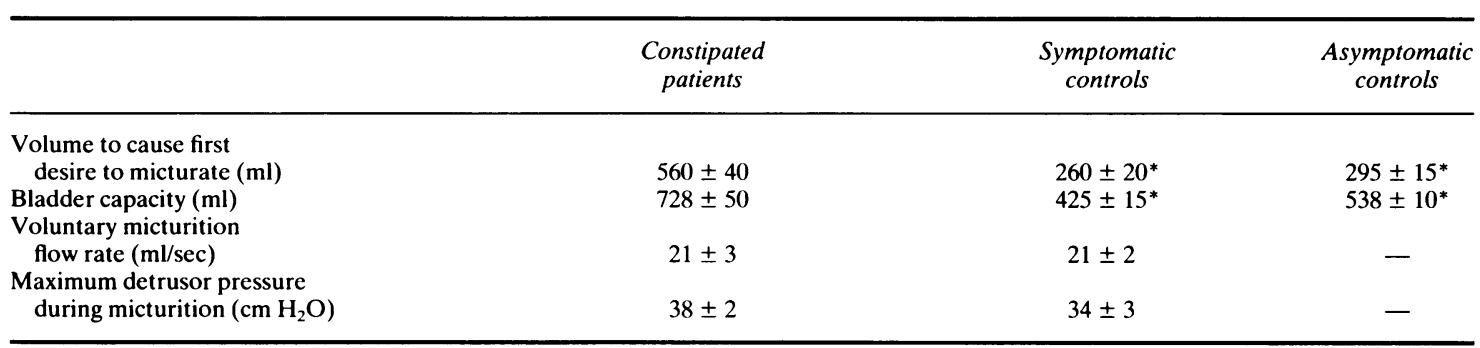

Results expressed as mean $\pm \mathrm{SEM} ;{ }^{*}=$ significantly different compared with patients $(\mathrm{p}<0 \cdot 001)$; statistical analysis by Student's $t$ test . 
Table 4 Bladder pressure during bladder filling

\begin{tabular}{lccc}
\hline & \multicolumn{2}{c}{$\begin{array}{c}\text { Bladder pressures } \\
\text { mm Hg (mean } \pm \text { SEM) }\end{array}$} \\
\cline { 2 - 3 } Bladder volume & Constipated & Controls & \\
\hline $100 \mathrm{ml}$ & $2 \pm 1$ & $2 \pm 1$ & NS \\
$200 \mathrm{ml}$ & $4 \pm 1$ & $4 \pm 1$ & NS \\
$300 \mathrm{ml}$ & $6 \pm 1$ & $6 \pm 1$ & NS \\
$400 \mathrm{ml}$ & $10 \pm 3$ & $8 \pm 2$ & NS \\
\hline
\end{tabular}

Statistical analysis by Student's $t$ test NS $=$ not significant $(p>0.05)$.

\section{Voiding}

Flow rates and maximum bladder pressures during , micturition were normal (Table 3). There was no radiological evidence of any outlet obstruction or failure of the urethral sphincter to relax.

\section{Discussion}

The results of this study show analogous abnormalities in bladder and rectal function in patients with constipation. The volumes required to induce a desire to micturate and a desire to defecate in constipated patients are both higher than in controls, and the maximum tolerable capacities of the bladder and the rectum are also higher in constipated patients. Despite this the rectal and bladder pressures at equivalent filling volumes and hence the compliance of the two organs were similar for the constipated patients compared with the controls. This suggests that the primary abnormality is not one of increased capacity, but that constipated patients have a similar blunting of sensation in the bladder and in the rectum. It is possible that the alteration in rectal sensation may occur as an adaptation to rectal distension caused by outlet obstruction, as none of the patients relaxed their anal sphincters during attempted defecation and eight of 10 patients actually showed an increase in external sphincter activity at that time, but if that were the case one might expect an increase in rectal compliance and this has not been found in this case nor in a large study of a group of similar patients. ${ }^{\prime}$

Do patients with constipation have a similar functional obstruction to the bladder outlet? Although we did not record from the urethral sphincter at that time, flow rates and maximum bladder pressures were quite normal and there was no radiological evidence of an outlet obstruction or failure of the sphincter to relax. Thus, if the lack of bladder and rectal sensitivity are mediated by the same mechanism, this is probably related to a primary disturbance in the sensory innervation.

This work was supported by grants from Birthright and the Trent, North West and Manchester Health Authorities.

\section{References}

1 Bannister JJ, Timms JM, Barfield LJ, Donnelly TC, Read NW. Physiological studies in young women with chronic constipation. Int J Colorect Dis 1986; 1: 175-82.

2 Preston DM, Lennard-Jones JE. Severe chronic constipation of young women: idiopathic slow transit constipation'. Gut 1986; 27 : 41-8.

3 Abdel-Rahman M, Tetreault L, Toppercer A, et al. Urodynamics in patients with colonic inertia. Urology 1981; 18: 428-32.

4 Watier A, Devroede G, Duranceau A, et al. Constipation with colonic inertia. A manifestation of systemic disease? Dig Dis Sci 1983; 28: 1025-33.

5 Read MG, Read NW, Barber DC, Duthie HL. Effect of loperamide on anal sphincter function in patients complaining of chronic diarrhoea with faecal incontinence and urgency. Dig Dis Sci 1982; 27: 807-14.

6 Basmajian JV, Stecko G. A new bipolar electrode for electromyography. J Appl Physiol 1962; $17: 849$.

7 Bates CP, Whiteside CS, Turner-Warwick R. Synchronous cine/pressure/flow cystourethrography with special reference to stress and urge incontinence. Br J Urol 1970; 42: 714-23. 